\title{
The intergenerational correlation of employment in Europe: A cross-country analysis*
}

\author{
José Ignacio Giménez-Nadal, University of Zaragoza, BIFI (Spain), CTUR (UK) \\ José Alberto Molina, University of Zaragoza, BIFI (Spain), IZA (Germany) \\ Jorge Velilla, University of La Rioja (Spain)
}

\begin{abstract}
We analyze the long-run intergenerational correlation of employment in Europe, providing cross-country evidence. Using the 2011 special module on Intergenerational Transmission, from the European Union Statistics on Income and Living Conditions (EU-SILC), we analyze the correlation between the current employment status of respondents, and that of their parents when respondents were 14 years old, in nine European countries. Estimates show that the intergenerational correlation of employment varies across countries and by gender, and is, in most cases, small or non-statistically significant.
\end{abstract}

Keywords: Intergenerational transmission; employment; EU-SILC data.

*J.I. Gimenez-Nadal: ngimenez@unizar.es, J.A. Molina: jamolina@unizar.es, J. Velilla: jorge.velilla@unirioja.es. Correspondence to J. Velilla. Department of Economics and Business Studies, University of La Rioja.

Acknowledgement: This paper has benefitted from funding from the Government of Aragón (Project S32_17R, co-financed by FEDER 2014-2020). J. Velilla gratefully acknowledges funding from the Government of Aragón Doctoral Grants (Program FSE Aragón 2014-2020). 


\section{Introduction}

This paper explores the intergenerational correlation of employment, with comparisons across nine European countries. Intergenerational transmission refers to how and to what extent certain factors can be transmitted from parents to children, including income and poverty, human capital, human development, and occupational choices. The existing research has identified the intergenerational transmission of employment and unemployment, although the literature on employment is scarce (Galassi et al., 2019). Transmission of employment and unemployment also supposes a particular case of intergenerational transmission of poverty, which has received significant attention in recent years.

The literature has shown a positive correlation between young workers' employment and unemployment status, and that of their parents, in various countries (O'Neill and Sweetman, 1998; Bratberget al., 2008; Ekhaugen, 2009). Nevertheless, there is no consensus as to the extent of these transmissions, with results that differ significantly among countries and methods. Within this framework, we explore the intergenerational transmission of employment (vs. unemployment) in nine European countries, estimating the relationship between the labor status of adults and that of their parents when those adults were 14 years old. We use the 2011 special module on Intergenerational Transmissions of the EU-SILC data, and estimates show either a small or a non-statistically significant intergenerational correlation of employment and provide a quantitative estimate for that relationship.

Our results show intergenerational correlations are not homogeneous across the nine analyzed countries. The fact that we use harmonized data and the same method of analysis, means that cross-country differences are due to differing country channels, and are not an artifact of the data and methods used. To the best of our knowledge, this paper represents the first comparable cross-country analysis of the intergenerational correlation of employment status.

\section{Data and variables}

We use data from Eurostat's 2011 EU-SILC Special Module on Intergenerational Transmission, covering the following countries: Austria, Belgium, France, Greece, Luxembourg, the Netherlands, Spain, Sweden, and the UK. The main purpose of this module is to collect 
information about household and parents' characteristics when respondents were 14 years old, for individuals between 25 and 59 years old, where fathers (mothers) refer to the individual that the respondent considers their father (mother). The analysis of intergenerational transmission is often identified as long-term effects, and thus we aim to analyze the correlations between the current employment status of individuals, and the past employment status of their parents (Solon, 1992, 2002).

The sample is restricted to individuals for whom there is information on both parents. ${ }^{1}$ The employment status of individuals is self-reported, and we define employed workers as those individuals who are either employees or self-employed. We omit from the sample those respondents who are students, disabled, retired, or in compulsory military service, which leaves unemployed workers and individuals fulfilling domestic tasks as "non-working" individuals.

The EU-SILC data allows us to define certain control variables. This includes the gender of individuals, age and age squared, the marital status, the maximum level of education, the household disposable income, the type of dwelling, and the number of children. We also define, from the special module, certain socio-demographics of parents when respondents where 14 years old: age, education level, immigrant status, employment status (defined analogously to respondents' employment), the number of children, and the household financial situation. ${ }^{2}$ Summary statistics are shown in Table A1 in the Appendix.

\section{Empirical results}

We regress the current employment status of respondents, in terms of their parents' employment. Assume that $i$ represents the reference individual of household $j$, and that $M$ and $F$ refer to the mother and the father. The following equation is estimated using OLS:

$$
E_{i j}=\beta_{0}+\beta_{1} X_{i j}+\sum_{k=M, F}\left(\beta_{2 k} E_{k j}+\beta_{3 k} X_{k j}\right)+\beta_{4} X_{j}^{I T D}+\varepsilon_{i j}
$$

\footnotetext{
${ }^{1}$ The sample of individuals for whom there is only information for the father or the mother is small; these results are available upon request.

${ }^{2}$ It is important to control for household finances, both at the current date and at the date of the special module (see, e.g., Borisov and Pissarides, 2019).
} 
where $E_{i j}$ is a dummy variable indicating whether individuals are employed (1) or unemployed (0); $E_{k j}$ is a dummy identifying employed parents, $k=M, F ; X_{i j}, X_{k j}$, and $X_{j}^{I T D}$ represent control variables of individuals, households, and parents; and $\varepsilon_{i j}$ represents the error term. ${ }^{3}$ Equation (1) is estimated by country, and separately for men and women. ${ }^{4}$ All the estimates include sample weights, and different controls at the country-year level (for the year of the special module): unemployment rates, fertility level, female labor force participation, and social norms towards working women, defined from the European Values Surveys. We also control for countries' current nest-leaving index, defined by gender and age groups.

The main coefficients of interest in Equation (1) are those associated to parents' employment dummy variables, $\beta_{2 M}$ and $\beta_{2 F}$. These coefficients represent the change in the probability of respondents being employed at the current date (relative to non-working respondents), conditional on the mother (father) being employed when the respondents were 14 years old. Furthermore, these relationships are estimated net of respondents, parents, and family observable characteristics. The interpretation of these coefficients is then similar to the wellknown intergenerational elasticities (e.g., Solon, 2002; Black and Devereux, 2010), which capture intergenerational mobility in a single parameter. However, the interpretation is slightly different, given the dichotomy of the dependent and main explanatory variables

Table 1 shows the estimates of Equation (1). (Additional coefficients are available upon request.) Among men, the coefficients of interest are not statistically significant in Austria, Belgium, Greece, the Netherlands, Spain, and Sweden, as the employment status of parents are not correlated with the employment status of respondents. In France and the UK, estimates reveal a positive and statistically significant correlation between the employment status of respondents and that of their mothers. We find a positive and statistically significant correlation between the employment status of the father and the respondents in Luxembourg. Estimates for female respondents show that the coefficients of interest are not statistically significant at standard levels in Greece, Sweden, and the UK, whereas in Belgium, the Netherlands, and Spain the correlation between the employment status of women and that of their fathers is negative

\footnotetext{
${ }^{3}$ We have alternatively estimated logistic regression models, with the main results remaining qualitatively unchanged (see Table A2 in the Appendix).

${ }^{4}$ We have estimated potential multicollinearity. According to variance inflation factors, estimates do not suffer from this issue.
} 
and statistically significant. Thus, in these countries, results do not point to the existence of intergenerational transmission of employment. On the other hand, in Austria, France, and Luxembourg, results reveal a positive correlation between the employment status of women and their mothers, and in Luxembourg there is a positive and significant coefficient associated with the father.

All in all, cross-country estimates for men and women suggest that the intergenerational correlation of employment is not homogeneous, as differences in the estimated correlations are found by gender, and also between fathers and mothers. In general terms, the estimated intergenerational correlations are either small or not statistically significant. Furthermore, estimates reveal differences among countries, even when considering only the countries where these correlations are significant. These findings suggest that the channels of the intergenerational transmission of employment (vs non-working) differ in European countries, and a more comprehensive exploration is needed. Factors such as cross-country differences in tax schemes, gender roles regarding the role of men and women in society, and country context (Burda et al., 2013; Duernecker and Herrendorf, 2018; Gracia et al., 2019), may affect the intergenerational transmission of employment.

\section{Conclusions}

This paper empirically examines the intergenerational correlation of employment in Europe. Focusing on parents' labor status when the respondent was 14 years old, we find that crosscountry estimates are statistically significant only for men in France, Luxembourg, and the UK, and for women in Austria, France, and Luxembourg. The ultimate objective of this work is to record the significance of intergenerational transmission as a channel of employment status in European countries, using the same empirical specifications and data for a set of countries. Further research should focus on studying the different channels that may drive this transmission, such as culture, social norms, and the influence of certain skill-sets, that may help in understanding country differences.

The main contribution of this analysis is to use homogenized data to compare our nine European countries. Thus, differences among countries are not expected to arise from different data or methods. The paper contributes to the field of social mobility, in which the focus is set 
on changes in socioeconomic measures between different generations, given that we document how the employment status of parents is transmitted to their offspring. Different theories may explain these transmissions, such as role models that account for family background, the accumulation of human capital, certain abilities and behaviors, and "soft skills" (Raitano and Vona, 2015). Our results complement a relatively limited literature on the transmission of labor market outcomes (Herault and Kalb, 2016), but also a comparatively extensive number of studies on the transmission of earnings, income, human capital, or occupations (Solon, 2002; Corak et al., 2014). In this sense, future research could use the EU-SILC Special Module on Intergenerational Transmission to analyze different intergenerational linkages, including the intergenerational transmission of education, or occupational mobility across generations.

The analysis has certain limitations. Results do not allow us to talk about causal effects, given potential endogeneity. Second, estimates may represent a lower bound of the real correlation, as parents/respondents could have been employed before or after the interview/reference year. Finally, the data used throughout the analysis does not allow us to run an accurate analysis of cross-occupation differences, given the limited sample sizes.

\section{Disclosure statement}

The authors declare that there is no conflict of interest.

\section{References}

Black, S., and Devereux, P. (2010). Recent developments in intergenerational mobility. Handbook of Labor Economics, 4B: 1487-1541.

Borisov, G. V., and Pissarides, C. A. (2019). Intergenerational Earnings Mobility in Post-Soviet Russia. Economica, forthcoming.

Bratberg, E., Anti Nilsen, O., and Vaage, K. (2008). Job losses and child outcomes. Labour Economics, 15(4): 591-603.

Burda, M., Hamermesh, D., and Weil, P. (2013). Total work and gender: facts and possible explanations. Journal of Population Economics, 26(1): 239-261. 
Corak, M., Lindquist, M., and Mazumder, B. (2014). A comparison of upward and downward intergenerational mobility in Canada, Sweden and the United States. Labour Economics, 30: 185-200.

Duernecker, G., and Herrendorf, B. (2018). On the allocation of time - A quantitavie analysis of the rol of taxes and productivities. European Economic Review, 102(1):169-187.

Ekhaugen, T. (2009). Extracting the causal component from the intergenerational correlation in unemployment. Journal of Population Economics, 22(1): 97-113.

Galassi, G., Koll, D. and Mayr, L. (2019). The intergenerational correlation of employment: Is there a role for work culture? IZA DP 12595.

Gracia, P., Garcia-Roman, J., Oinas, T., and Anttila, T. (2019). Child and Adolescent Time Use: A Cross-National Study. Journal of Marriage and Family, 82(4): 1304-1325.

Herault, N., and Kalb, G. (2016). Intergenerational correlation of labor market outcomes. Review of Economics of the Household, 14: 231-249.

O’Neill, D., and Sweetman, O. (1998). Intergenerational mobility in Britain: Evidence from unemployment patterns. Oxford Bulletin of Economics and statistics, 60(4): 431-447.

Raitano, M., and Vona, F. (2015). Direct and indirect influences of parental background on children's earnings: A comparison across countries and genders. The Manchester School, 83(4): 423-450.

Solon, G. (1992). Intergenerational income mobility in the United States. The American Economic Review, 82(3), 393-408.

Solon, G. (2002). Cross-country differences in intergenerational earnings mobility. Journal of Economic Perspectives, 16(3), 59-66. 
Table 1. Main estimates

\begin{tabular}{|c|c|c|c|c|c|c|c|c|c|}
\hline A) MEN & $\begin{array}{l}\text { Austria } \\
\text { (1) }\end{array}$ & $\begin{array}{l}\text { Belgium } \\
\text { (2) }\end{array}$ & $\begin{array}{l}\text { France } \\
\text { (3) }\end{array}$ & $\begin{array}{l}\text { Greece } \\
(4)\end{array}$ & $\begin{array}{l}\text { Luxemb. } \\
\text { (5) }\end{array}$ & $\begin{array}{l}\text { Netherl. } \\
\text { (6) }\end{array}$ & $\begin{array}{l}\text { Spain } \\
(7)\end{array}$ & $\begin{array}{c}\text { Sweden } \\
(8)\end{array}$ & $\begin{array}{l}\text { UK } \\
(9) \\
\end{array}$ \\
\hline $\begin{array}{l}\text { Father employed } \\
\text { Mother employed }\end{array}$ & $\begin{array}{l}-0.016 \\
-0.003\end{array}$ & $\begin{array}{l}0.004 \\
0.004\end{array}$ & $\begin{array}{c}0.012 \\
0.013^{* *}\end{array}$ & $\begin{array}{c}-0.005 \\
0.049\end{array}$ & $\begin{array}{l}0.038^{*} \\
-0.009\end{array}$ & $\begin{array}{l}-0.006 \\
-0.001\end{array}$ & $\begin{array}{l}0.000 \\
0.016\end{array}$ & $\begin{array}{l}-0.013 \\
-0.006\end{array}$ & $\begin{array}{c}0.022 \\
0.015^{* *}\end{array}$ \\
\hline $\begin{array}{l}\text { All controls } \\
\text { R-squared } \\
\text { N. Observations }\end{array}$ & $\begin{array}{c}\text { Yes } \\
0.137 \\
2,408\end{array}$ & $\begin{array}{c}\text { Yes } \\
0.048 \\
2,243\end{array}$ & $\begin{array}{l}\text { Yes } \\
0.04 \\
6,170\end{array}$ & $\begin{array}{c}\text { Yes } \\
0.08 \\
1,497\end{array}$ & $\begin{array}{c}\text { Yes } \\
0.059 \\
8,685\end{array}$ & $\begin{array}{l}\text { Yes } \\
0.052 \\
2,567\end{array}$ & $\begin{array}{l}\text { Yes } \\
0.085 \\
2,146\end{array}$ & $\begin{array}{l}\text { Yes } \\
0.115 \\
748\end{array}$ & $\begin{array}{l}\text { Yes } \\
0.076 \\
2,069\end{array}$ \\
\hline B) WOMEN & Austria & Belgium & France & Greece & Luxemb. & Netherl. & Spain & Sweden & UK \\
\hline $\begin{array}{l}\text { Father employed } \\
\text { Mother employed }\end{array}$ & $\begin{array}{l}-0.044 \\
0.039 * * *\end{array}$ & $\begin{array}{c}-0.051 * \\
0.018\end{array}$ & $\begin{array}{c}0.037 \\
0.039 * * *\end{array}$ & $\begin{array}{c}0.025 \\
-0.029\end{array}$ & $\begin{array}{l}0.097 * * * \\
0.059 * * *\end{array}$ & $\begin{array}{c}-0.034 * * * \\
-0.002\end{array}$ & $\begin{array}{c}-0.051^{* * *} \\
-0.002\end{array}$ & $\begin{array}{r}0.062 \\
-0.001\end{array}$ & $\begin{array}{l}0.019 \\
0.008\end{array}$ \\
\hline $\begin{array}{l}\text { All controls } \\
\text { R-squared } \\
\text { N. Observations }\end{array}$ & $\begin{array}{c}\text { Yes } \\
0.105 \\
2,604\end{array}$ & $\begin{array}{c}\text { Yes } \\
0.099 \\
2,356\end{array}$ & $\begin{array}{l}\text { Yes } \\
0.067 \\
6,588\end{array}$ & $\begin{array}{l}\text { Yes } \\
0.102 \\
1,379\end{array}$ & $\begin{array}{c}\text { Yes } \\
0.092 \\
9,212\end{array}$ & $\begin{array}{c}\text { Yes } \\
0.048 \\
2,825\end{array}$ & $\begin{array}{c}\text { Yes } \\
0.03 \\
2,451\end{array}$ & $\begin{array}{l}\text { Yes } \\
0.18 \\
824\end{array}$ & $\begin{array}{l}\text { Yes } \\
0.115 \\
2,570\end{array}$ \\
\hline
\end{tabular}

